\title{
A New Cytoplasmic Bar-like Structure Seen in Type II Alveolar Cells of Rat Lungs
}

\author{
Sanae Shimura, Tooru Aoki, Shigkru Sato and \\ Tamotsu Takishima \\ The First Department of Internal Medicine, Tohoku University \\ School of Medicine, Sendai 980
}

Shmura, S., Aokr, T., Sato, S. and Takishima, T. A New Cytoplasmic Bar-like Structure Seen in Type II Alveolar Cells of Rat Lungs. Tohoku J. exp. Med., 1980, 131 (4), 409-410 — Type II alveolar cells from healthy (control) and from pilocarpine-treated rats were studied using transmission electron microscopy of ultra-thin sections and freeze fracture replicas. In freeze-fracture preparations, a bar-like laminated structure about $0.4 \mu \mathrm{m}$ in diameter and $1 \sim 6$ $\mu \mathrm{m}$ in length was found in type II alveolar cells; it seemed to be identical to the membrane-bound slits containing electron dense materials which were also observed in ultra-thin sections. The frequency of this structure in the cells increased together with an increase in the number of lamellar bodies after injection of pilocarpine, suggesting a close connection between the bar-like structure and the formation of pulmonary surfactant. - rat lung; alveoli; fine structure; new cytoplasmic inclusion

Currently, type II alveolar cells are thought to be the source of pulmonary surfactant complexes, and pilocarpine has been shown to stimulate the secretion of these cells (Goldenberg et al. 1969). However, type II alveolar cells from pilocarpine-treated animals have not been investigated in detail from the viewpoint of ultrastructure in connection with the mechanism by which the secretion is overproduced.

Twenty-two adult, white, male Wistar rats weighing approximately $230 \mathrm{~g}$ were given a single subcutaneous injection of $15 \mathrm{mg}$ per $100 \mathrm{~g}$ body weight of pilocarpine and sacrificed by exsanguination at intervals of $1 / 2,1,2$ and $4 \mathrm{hr}$ after the injection. The left lung was fixed in $2 \%$ glutaraldehyde with postfixation in $1 \% \mathrm{OsO}_{4}$, followed by dehydration in ascending concentrations of acetone, embedded in Epon 812 and sectioned. The ultrathin sections were stained with uranyl acetate and lead hydroxide. The right lung was chopped into $1 \sim 2 \mathrm{~mm}$ cubes which were immersed in $2 \%$ glutaraldehyde for $4 \mathrm{hr}$ at $4^{\circ} \mathrm{C}$ and then transferred to $30 \%$ glycerol for $10 \mathrm{hr}$ at $4^{\circ} \mathrm{C}$. The tissue cubes were frozen in liquid Freon and were then quickly transferred onto the precooled specimen stage in a Freeze Fracturing and Etching unit (block type) equipped with a JEE-4C Vaccum Coater. Fractured faces of the tissues were etched for 2 min at $-110^{\circ} \mathrm{C}$ immediately followed by shadowing with platinum and by replication with carbon. The tissues were then decomposed and the free replica films were washed and mounted on copper grids.

The increase in size and number of lamellar bodies in the type II alveolar cells and accumulation of myelin figures in alveoli were most prominent in rats killed at $2 \mathrm{hr}$ after injection of pilocarpine. In freeze-fracture preparations, a bar-like structure approximately $0.4 \mu \mathrm{m}$ in diameter and $1 \sim 6 \mu \mathrm{m}$ in length, which showed laminations in the cross sections (Fig. 1a) and a telescope-like appearance in the longitudinal sections (Fig. 1b), was found in type II alveolar cells. The frequency of this structure observed in the cells increased

Received for publication, November $19,1979$. 
together with the increase in the number of lamellar bodies after injection of pilocarpine, whereas only very few were observed in the cells from control rats. It seemed to be indentical to membrane-bound slits of various sizes containing electron dense materials with a periodicity of $50 \AA$ observed in ultra-thin sections (Fig. 2), which also increased in number in the cells from pilocarpine-treated rats.

The bar-like structure has not been demonstrated previously and, although its significance is still uncertain, the ultrastructural findings mentioned above suggest that it may play an important role in the metabolism of pulmonary surfactant.

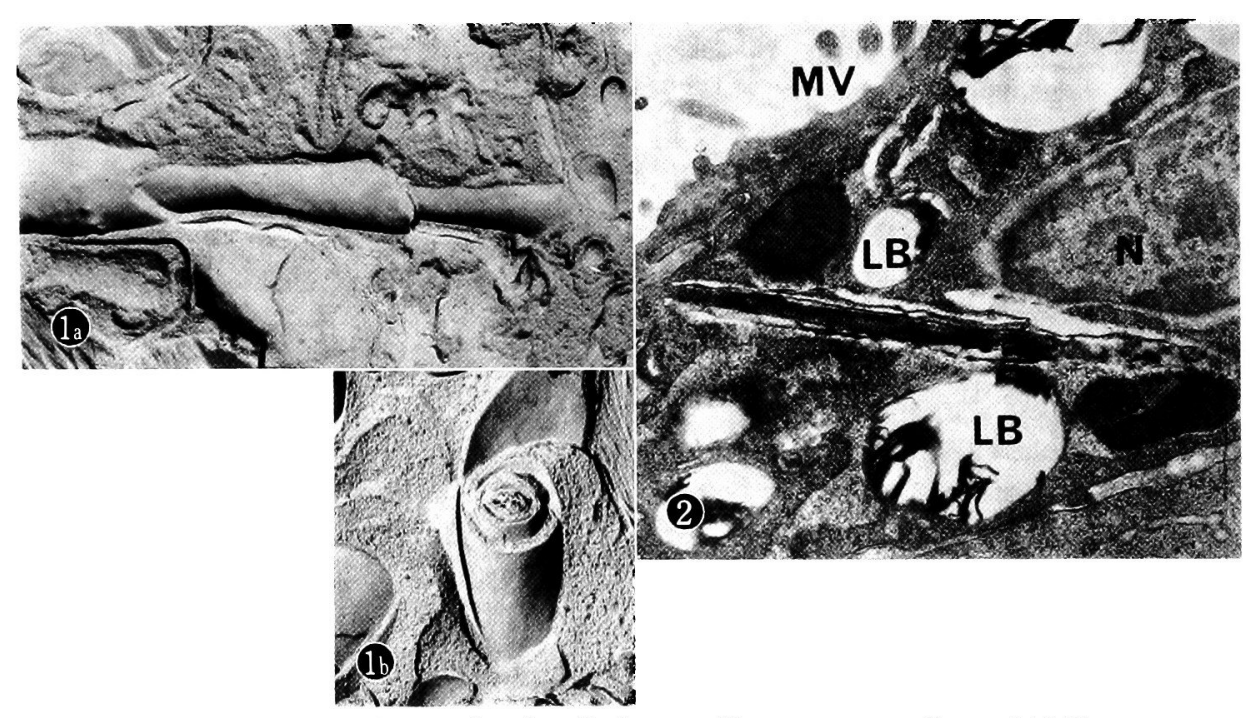

Fig. 1a. Freeze-fracture image showing "telescope-like appearance". $\times 24,000$.

Fig. 1b. Freeze-fracture image of the cross section of the bar-like structure showing laminations. $\times 32,000$.

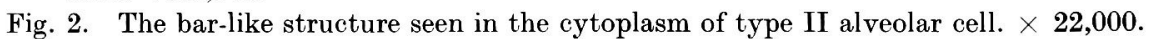

LB, lamellar body; MV, microvilli; N, nucleus.

\section{Reference}

1) Goldenberg, V.E., Buckingham, S. \& Sommers, S.C. (1969) Pilocarpine stimulation of granular pneumocyte secretion. Lab. Invest., 20, 147-158. 